\title{
Enriched ammonia-tolerant methanogenic cultures as bioaugmentation inocula in continuous biomethanation processes
}

Fotidis, Ioannis; Treu, Laura; Angelidaki, Irini

Published in:

Journal of Cleaner Production

Link to article, DOI:

10.1016/j.jclepro.2017.08.151

Publication date:

2017

Document Version

Peer reviewed version

Link back to DTU Orbit

Citation (APA):

Fotidis, I., Treu, L., \& Angelidaki, I. (2017). Enriched ammonia-tolerant methanogenic cultures as bioaugmentation inocula in continuous biomethanation processes. Journal of Cleaner Production, 166, 13051313. https://doi.org/10.1016/j.jclepro.2017.08.151

\section{General rights}

Copyright and moral rights for the publications made accessible in the public portal are retained by the authors and/or other copyright owners and it is a condition of accessing publications that users recognise and abide by the legal requirements associated with these rights.

- Users may download and print one copy of any publication from the public portal for the purpose of private study or research.

- You may not further distribute the material or use it for any profit-making activity or commercial gain

- You may freely distribute the URL identifying the publication in the public portal 


\section{Accepted Manuscript}

Enriched ammonia-tolerant methanogenic cultures as bioaugmentation inocula in continuous biomethanation processes

loannis A. Fotidis, Laura Treu, Irini Angelidaki

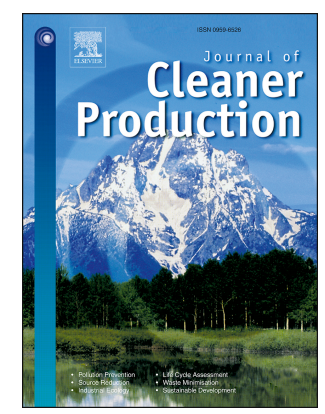

PII:

S0959-6526(17)31880-2

DOI:

10.1016/j.jclepro.2017.08.151

Reference: JCLP 10410

To appear in: Journal of Cleaner Production

Received Date: 1 June 2017

Revised Date: 17 August 2017

Accepted Date: 17 August 2017

Please cite this article as: Fotidis IA, Treu L, Angelidaki I, Enriched ammonia-tolerant methanogenic cultures as bioaugmentation inocula in continuous biomethanation processes, Journal of Cleaner Production (2017), doi: 10.1016/j.jclepro.2017.08.151.

This is a PDF file of an unedited manuscript that has been accepted for publication. As a service to our customers we are providing this early version of the manuscript. The manuscript will undergo copyediting, typesetting, and review of the resulting proof before it is published in its final form. Please note that during the production process errors may be discovered which could affect the content, and all legal disclaimers that apply to the journal pertain. 


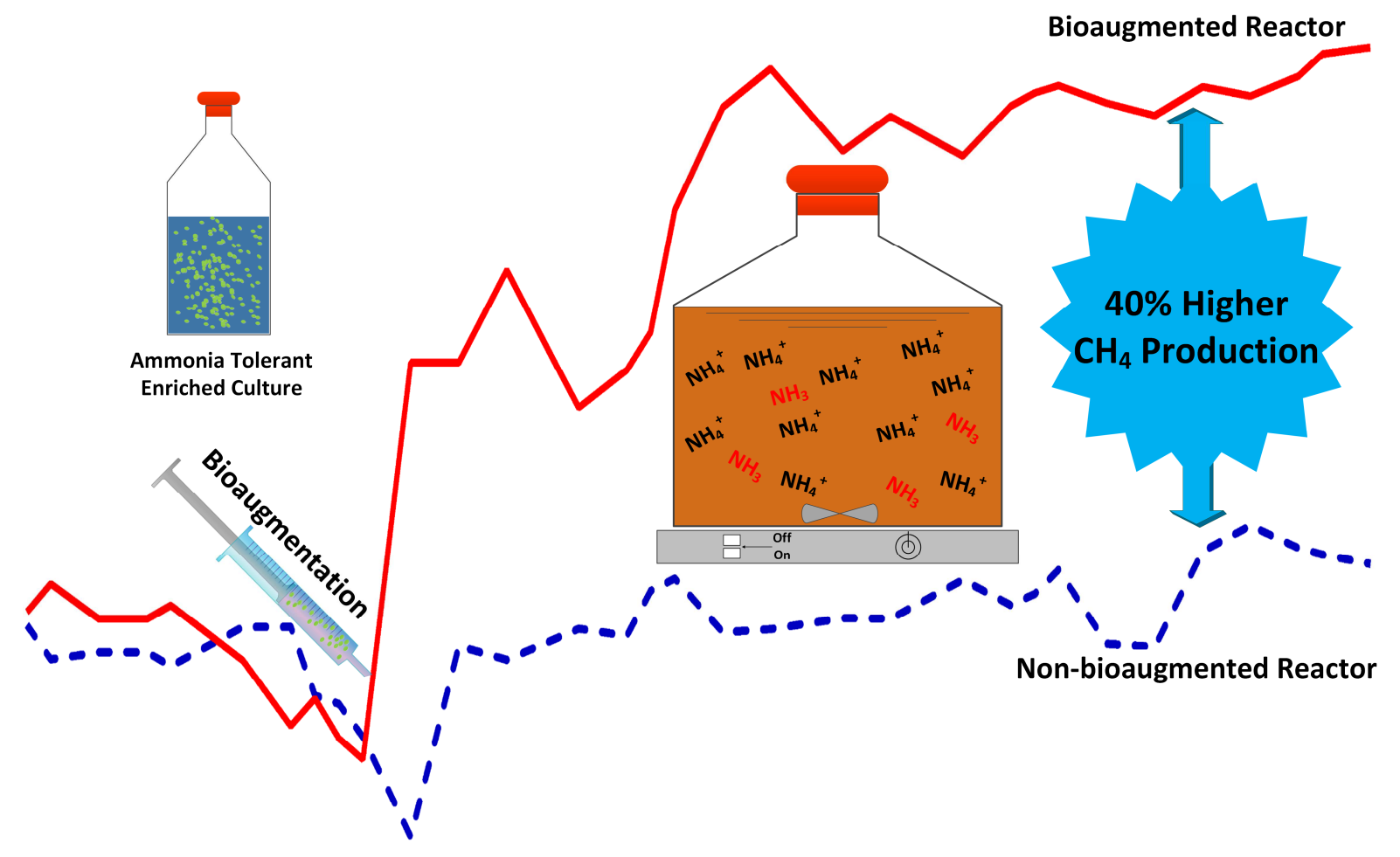




\section{Enriched ammonia-tolerant methanogenic cultures as bioaugmentation inocula in continuous biomethanation processes}

Ioannis A. Fotidis*, Laura Treu, Irini Angelidaki

Department of Environmental Engineering, Technical University of Denmark, Bygningstorvet Bygning 115, DK-2800 Kgs. Lyngby, Denmark

*Corresponding author: Ioannis A. Fotidis, Department of Environmental Engineering,

Technical University of Denmark, Bygningstorvet Bygning 115, DK-2800 Kgs. Lyngby,

Denmark. Tel.:+45 45251418, Fax: +45 45932850, Email: ioanf@env.dtu.dk 
Abstract

Many ammonia-rich biomass sources, such as manures and protein-rich substrates, are potential inhibitors of the anaerobic digestion (AD) process. It was previously demonstrated that bioaugmentation of Methanoculleus bourgensis $\mathrm{MS}^{\mathrm{T}}$ in an ammonia inhibited process in a continuous stirred tank reactor (CSTR), resulted in up to $90 \%$ recovery of the methane production compared to the uninhibited production. However, cultivation of pure strains has practical difficulties due to the need of special growth media and sterile conditions. In contrast, acclimatized enriched cultures have minor sterility requirements. In the current study, an enriched ammonia-tolerant methanogenic culture was bioaugmented in a CSTR reactor operating under ammonia-induced, inhibited-steady-state. The results demonstrated that bioaugmentation, completely counteracted the ammonia toxicity effect. This indicates that a commercial application of bioaugmentation could improve up to $36 \%$ the methane production, the greenhouse gas reduction efficiency and the gross revenue of ammonia inhibited full scale biogas reactors. 16S rRNA gene sequencing showed that bioaugmentation changed the microbial composition of the reactors resulting in higher bacterial and lower archaeal community diversity. The bioaugmented reactor showed a fourfold increase of the abundance of the bioaugmented methanogens compared to the control reactor. This indicates that ammonia-tolerant methanogens established well in the ammonia-inhibited reactor and dominated over the domestic methanogenic population. Finally, this study showed that the enriched culture alleviated ammonia toxicity $25 \%$ more efficiently than the previously used pure culture.

\section{Keywords}

Ammonia toxicity; Archaeon; Aceticlastic methanogen; Bacterium; Hydrogenotrophic methanogen. 


\section{Nomenclature}

$\begin{array}{ll}\text { AD } & \text { Anaerobic digestion } \\ \text { ANOVA } & \text { Analysis of variance } \\ \text { CSTR } & \text { Ammonia-oxidizing archaea } \\ \text { HRT } & \text { Continuous stirred tank reactor } \\ \text { OD } 600 & \text { Optical density at } 600 \text { nm } \\ \text { OLR } & \text { Organic loading rate } \\ \text { OTU } & \text { Operational taxonomic unit } \\ \text { SAO } & \text { Syntrophic acetate oxidation } \\ \text { SAOB } & \text { Syntrophic acetate oxidizing bacterium } \\ \text { SRT } & \text { Solid retention time } \\ \text { TS } & \text { Total solid } \\ \text { VFA } & \text { Volatile fatty acid } \\ \text { VS } & \text { Volatile solid } \\ \mu_{\text {max }} & \text { Maximum growth rate }\end{array}$

\section{Introduction}

Vast amounts of ammonia-rich organic wastes are produced yearly from the agricultural and the food industrial sectors (Kovács et al., 2013). Anaerobic digestion (AD) is one of the most effective methods to treat this waste, as it provides energy (methane) and a bio-fertilizer (digestate) (Tampio et al., 2016). Moreover, some manures (e.g. pig, poultry etc.) that are often used as substrates in biogas reactors contain high amounts of urea. Ammonia is a wellknown inhibitor of the AD process (Westerholm et al., 2015). It has been widely shown that free ammonia (unionised, $\mathrm{NH}_{3}$ ) is the most toxic form of the total ammonia $\left(\mathrm{NH}_{4}{ }^{+}+\mathrm{NH}_{3}\right.$ ) for 
the methanogenic communities mediating the AD process (Rajagopal et al., 2013). The $\mathrm{NH}_{3}$ levels depend on the total ammonia concentration in a reactor and on the $\mathrm{NH}_{4}{ }^{+} / \mathrm{NH}_{3}$ equilibrium, which is affected by the temperature and the $\mathrm{pH}$ (Yenigün and Demirel, 2013).

Many solutions have been proposed to solve the ammonia inhibition problem. Up to now, the two most common methods are lowering the operating temperature and diluting the reactor content with water (Kelleher et al., 2002; Nielsen and Angelidaki, 2008).

Nevertheless, these methods can counteract the ammonia toxicity only to a limited extend, are uneconomical and do not provide a permanent solution (Massé et al., 2014).

Europe has currently more than 17,240 biogas plants and most of them use combined heat and power (CHP) units to generate electricity on site, with an average efficiency of $40 \%$ (European Biogas Association, 2015; Herbes et al., 2016). At the same time, it has been found that several of the European biogas reactors are seriously affected by ammonia toxicity, leaving unexploited more than $30 \%$ of their methane potential, while operating in an ammonia induced inhibited-steady-state (Duan et al., 2012; Fotidis et al., 2014a). This suboptimal, but apparently stable process is resulting in severe operational problems with increased $\mathrm{CO}_{2}$ footprint. In Europe, the minimum price for the electricity produced from biogas (using residual resources as feedstock) is $0.11 € \mathrm{kWh}_{(\mathrm{e})}{ }^{-1}$ and the total installed capacity is 8,333 $\mathrm{MW}_{(\mathrm{e})}$ (European Biogas Association, 2015); thus the European biogas industry suffers significant economic losses due to the ammonia toxicity. At present, to secure an uninhibited $\mathrm{AD}$ process, biogas plant operators minimize or completely avoid the high ammonia containing feedstocks. Nevertheless, it is imperative to find an alternative and reliable solution for the treatment of the vast amounts of high ammonia containing ammoniarich substrates and alleviate their ammonia inhibitory effect in continuous biomethanation processes.

It has been previously reported that aceticlastic methanogens are sensitive to ammonia 
(Chen et al., 2008; Westerholm et al., 2011; Yenigün and Demirel, 2013). There is however, another metabolic pathway, the syntrophic acetate oxidation (SAO) pathway, where acetate is oxidized by syntrophic acetate oxidizing bacteria (SAOB) to hydrogen and carbon dioxide, followed by hydrogenotrophic methanogenesis (Westerholm et al., 2016). The SAO pathway is much less liable to ammonia inhibition (Moestedt et al., 2016; Westerholm et al., 2011). The use of ammonia-tolerant hydrogenotrophic methanogenic cultures could provide an alternative solution to overcome ammonia inhibition in AD process. Specifically, Costa et al. (2012) have suggested bioaugmentation as the potential method to deliver and establish these ammonia-tolerant cultures in ammonia inhibited continuous anaerobic reactors. Based on that Fotidis et al. (2014b) have successfully bioaugmented an ammonia-tolerant pure culture (Methanoculleus bourgensis $\mathrm{MS}^{\mathrm{T}}$ ) in a continuous reactor. Nevertheless, the cultivation of pure cultures to be used as bioaugmentation inocula has specific technical difficulties and is cost-expensive due to required sterile conditions and special growth media (De Roy et al., 2014). Contrary to pure cultures, ammonia acclimatized (enriched) cultures have lower requirements to sterility (Narihiro et al., 2015). Additionally, adaptation of the AD process to high ammonia loads is well established (Rajagopal et al., 2013; Tian et al., 2017). It is hypothesized that due to the acclimation process, these complex communities could be more robust and thus, better biomethanation inocula than a pure strain. Enriched ammonia-tolerant methanogenic cultures have been used before as bioaugmentation inocula in batch reactors with high ammonia levels (Wilson et al., 2013). However, these enriched cultures were never assessed as bioaugmentation inocula in continuous anaerobic reactors where the washout of the inoculated microorganisms poses a big challenge (Han et al., 2016; Sivagurunathan et al., 2015; Westerholm et al., 2016).

Based on the above, three major aims were addressed in the current study. First, to use an enriched ammonia-tolerant methanogenic culture as a bioaugmentation inoculum in a 
continuous stirred tank reactor (CSTR) operating under ammonia induced inhibited-steadystate. Second, based on the lab scale results, to define the effect of bioaugmentation on the energy production, greenhouse gas (GHG) emissions and gross revenue of the biogas reactor compared to a reactor operating under ammonia induced inhibited-steady-state. Third, to compare the data extracted from this study with the results derived from a previous study, which has been conducted under the same experimental conditions but with the use of a pure culture as bioaugmentation inoculum (Fotidis et al., 2014b).

\section{Materials and Methods}

\subsection{Ammonia-tolerant enriched culture}

The enriched ammonia-tolerant culture used in the bioaugmentation process was derived from a previous experiment (Fotidis et al., 2013), where inoculum from Hashøj Biogas plant (Denmark) was acclimatized to stepwise increased ammonia levels (up to $7 \mathrm{~g} \mathrm{NH}_{4}^{+}-\mathrm{N} \mathrm{L}^{-1}$ ) in batch reactors. Before introduction to the CSTR reactor, the enriched culture was incubated at $5 \mathrm{~g} \mathrm{NH}_{4}{ }^{+}-\mathrm{N} \mathrm{L}^{-1}$ in batch reactors with BA medium (Zehnder et al., 1980). The $\mathrm{pH}$ of the batch reactors was adjusted to $7.0 \pm 0.1$ using a $\mathrm{N}_{2}$ and $\mathrm{CO}_{2}$ gas mixture (4/1 on volume basis). Subsequently, $124.8 \mathrm{~mL}$ of $\mathrm{H}_{2}$ and $31.2 \mathrm{~mL}$ of $\mathrm{CO}_{2}$ were added in the headspace. All the bottles had $118 \mathrm{~mL}$ total and $40 \mathrm{~mL}$ working volumes and were incubated at $37 \pm 1^{\circ} \mathrm{C}$. The enriched culture showed hydrogenotrophic methanogenic pathway at $5 \mathrm{~g} \mathrm{NH}_{4}{ }^{+}-\mathrm{N} \mathrm{L}^{-1}$ as determined by radio labelled experiments using $\left[2-{ }^{14} \mathrm{C}\right]$ acetate as reported before (Fotidis et al., 2013). Finally, preliminary high-throughput 16 S rRNA gene sequencing analysis of the enriched culture showed that it consisted of a hydrogenotrophic methanogen (Methanoculleus spp.) and four primary bacteria (Tepidimicrobium spp., Aminobacterium spp., Petrimonas spp. and Defluviitoga spp.). 


\subsection{Inoculum and feedstock}

The inoculum used in the CSTR reactors was retrieved from a full-scale mesophilic anaerobic reactor (Hashøj Biogas, Denmark) fed with pig and cattle manure (>70\%) and organic waste $(>10 \%)$. All the dairy slurry derived from Hashøj municipality (Denmark) and was the primary feedstock used in the experiment. The slurry was sieved to remove coarse materials, thoroughly mixed to ensure homogeneity throughout the experiment and kept at 4 ${ }^{\circ} \mathrm{C}$ before used in the experiment. The basic characteristics of inoculum and feedstock are depicted in Table 1.

\subsection{Experimental setup}

The bioaugmentation experiment was performed in two identical glass CSTR reactors ( $\mathrm{R}_{\text {Enc }}$ : Enriched culture bioaugmentation and $\mathrm{R}_{\mathrm{Ct1}}$ : abiotic augmentation) with $2.3 \mathrm{~L}$ total and $1.8 \mathrm{~L}$ working volumes. Both reactors had organic loading rate (OLR) of $1.74 \mathrm{~g} \mathrm{VS} \mathrm{L}^{-1} \mathrm{~d}^{-1}$ and solid (SRT) and hydraulic (HRT) retention times of 24 days. Ammonium chloride was used as additional ammonia source. Each reactor's setup had a feedstock tank, a feeding peristaltic pump, an effluent tank, two magnetic stirrers, a water-displacement gas meter and an electrical heating jacketed system.

The complete bioaugmentation experiment was divided to six distinct experimental periods (P-1 to P-6). Both CSTR reactors started-up (data not shown) with an ammonia level in the feedstock of $1.65 \mathrm{~g} \mathrm{NH}_{4}{ }^{+}-\mathrm{N} \mathrm{L}^{-1}$ until they established a steady-state, (P-1, days 1-10). Ammonia levels were then stepwise increased in the feedstock at $3 \mathrm{~g} \mathrm{NH}_{4}{ }^{+}-\mathrm{N} \mathrm{L}^{-1}(\mathrm{P}-2$, days 11-31), $4 \mathrm{~g} \mathrm{NH}_{4}{ }^{+}-\mathrm{N} \mathrm{L}^{-1}$ (P-3, days 32-62) and $5 \mathrm{~g} \mathrm{NH}_{4}{ }^{+}-\mathrm{N} \mathrm{L}^{-1}$ (P-4, days 63-96). After ammonia concentration in the feedstock increased at $5 \mathrm{~g} \mathrm{NH}_{4}{ }^{+}-\mathrm{N} \mathrm{L}^{-1}$ (during P-4), an ammonia induced inhibited-steady-state was established (days 87-96) for both reactors. Addition of $100 \mathrm{~mL}$ of the enriched culture $\left(\mathrm{OD}_{600}=0.21-0.23\right.$ and $\mu_{\max }=0.024 \mathrm{~h}^{-1}$, from a 
batch culture at exponential growth phase) in the $\mathrm{R}_{\text {Enc }}$ reactor took place twice on P-5 (days 97 and 99$)$. At the same time, the same volume ( $200 \mathrm{~mL}$ in total $)$ of sterile BA medium with 5 $\mathrm{g} \mathrm{NH}_{4}{ }^{+}-\mathrm{N} \mathrm{L}^{-1}$, was also introduced in the reactor $\mathrm{R}_{\mathrm{Ctl}}$, to apply the same hydraulic effect as the bioaugmentation inoculum (abiotic augmentation). P-6 (days 100-142) of the experiment was defined as the period after the bioaugmentation and abiotic augmentation (i.e. the addition of sterile medium in reactor $\mathrm{R}_{\mathrm{Ctl}}$ to replicate the hydraulic effect that the bioaugmentation inoculum had on the $\mathrm{R}_{\mathrm{Enc}}$ ) processes took place. Throughout the duration of the experiment, both reactors were operating continuously and the HRT, the OLR and the ammonia levels in the feedstock (corresponding to each period), were kept stable. The maximum organic matter concertation delivered to the reactors during the bioaugmentation and abiotic augmentation, was less than $1 \%$ of the OLR and its effect on the methane production was considered to be statistically negligible. Finally, the total ammonia concentrations of the feedstock and the reactors, throughout the experiment, are depicted in Fig. S1 (Supplementary Material-Part A).

\subsection{Analyses}

Total solids (TS), volatile solids (VS), total Kjeldahl nitrogen, total ammonia and $\mathrm{pH}$ were determined according to APHA's Standard Methods (APHA, 2012). The $\mathrm{pH}$ was measured with a PHM99 LAB pH meter. The methane content in the biogas produced by the CSTR reactors was measured with GC-TCD (MGC 82-12, Mikrolab a/s, Denmark). The volatile fatty acids (VFA) were determined using gas-chromatograph (HP 5890 series II). The optical density at $600 \mathrm{~nm}\left(\mathrm{OD}_{600}\right)$ was determined with a Spectronic 20D+ Spectrophotometer (Thermoscientific, Soeborg, Denmark).

\subsection{DNA extraction and high-throughput 16S rRNA gene sequencing}

Both archaea and bacteria high-throughput 16S rRNA gene sequencing was performed in the CSTR reactors before (day 96, P-4) and after (day 121, P-6) bioaugmentation to elucidate 
any possible changes in the relative abundance of methanogenic populations. QIAamp DNA Stool Mini Kit (Qiagen Inc., Mississauga, Canada, Cat No. 51504) was used to treat the samples for total genomic DNA extraction as has been dictated by the manufacturer's instructions (Dokianakis et al., 2004). Nested PCR was used for archaea, with archaeaspecific primers 20f (5'-TTCCGGTTGATCCYGCCRG-3') and 958r (5'-

YCCGGCGTTGAMTCCAATT-3') for the first amplification round and ARC-344f (5'ACGGGGYGCAGCAGGCGCGA-3') and ARC-519r (5'-GWATTACCGCGGCKGCTG-3') for the second amplification round. For bacteria, PCR was performed with specific primers 341f 5' -CCTACGGGAGGCAGCAG-3' and 518r 5'-ATTACCGCGGCTGCTGG-3' for amplification. In all PCR amplifications, Taq PCR Core Kit (QIAGEN) was used with $1 \mu \mathrm{L}$ template DNA and 20 pmol of each primer. The PCR conditions for the first and second amplification were as described by Fotidis et al. (2014b). For purification and removal of the excess primer dimers and dNTPs from the PCR products, QIAquick spin columns (QIAGEN) were used. Subsequently, the samples were sent for barcoded libraries preparation and sequencing on an Ion Torrent PGM apparatus with 316 chip using the Ion Sequencing 200 kit (all Life Technologies, Inc., Paisley, United Kingdom) according to the standard protocol (Ion XpressTM Plus gDNA and Amplicon Library Preparation, Life technologies) (Luo et al., 2013).

\subsection{Microbial community data processing}

The raw sequence data were deposited at "sequence read archive" database (http://www.ncbi.nlm.nih.gov/sra) under accession numbers SRS1510840 and SRS15113331511335. Raw reads were analysed using CLC Workbench software (V.8.0.2) with Microbial genomics module plug in. A trimming procedure was applied to low quality reads according to default parameters provided by the software. Chimera crossover filter was also performed. Operational taxonomic units' (OTUs) phylogenetic assignment was performed with Multiple 
Sequence Comparison by Log- Expectation on trimmed (240 bp) sequences using Greengenes v13_5 database as reference (clustered at $97 \%$ ). OTU similarity cut-off was set at $97 \%$. The creation of new OTUs was allowed when taxonomy similarity percentage was lower than 80 $\%$ and the minimum occurrence was five reads. OTUs were aligned using MUSCLE software implemented in CLC software. Maximum Likelihood Phylogeny (tree) was performed with Neighbor Joining as construction method and with Jukes Cantor as nucleotide substitution model to estimate the evolutionary distance between sequences. Bootstrap analysis was performed with 100 replicates to test the certainty of the evolutionary relation and distance. Alpha diversity was measured based on number of OTUs, Chao 1 bias-corrected and Phylogenetic diversity. Beta Diversity represented as "principal coordinate analysis" of the 16S rRNA gene OTUs was obtained using Bray-Curtis matrix.

\section{Theory/calculation}

\subsection{Growth rate and maximum methane production}

The maximum growth rate $\left(\mu_{\max }\right)$ of the enriched culture was calculated from the slope of the linear part of the graph of the batch reactors methane production (natural logarithm) versus time as has been described before (Fotidis et al., 2014a). The methane production of both $\mathrm{R}_{\mathrm{Enc}}$ and $\mathrm{R}_{\mathrm{Ctl}}$ continuous reactors during $\mathrm{P}-1$ was considered as the maximum methane production (uninhibited) of the dairy slurry, which used to detect any changes in the performance of the two reactors throughout the experiment.

\subsection{Steady-state}

As steady-state was defined a quasi-steady-state (Venkiteshwaran et al., 2016), for at least a period of ten successive days with less than $10 \%$ variation in the methane production, VFA accumulation and $\mathrm{pH}$ fluctuation (Fotidis et al., 2016). 


\subsection{Statistics}

Analysis of variance (ANOVA) was used to define the statistically significant differences among the different methane productions. ANOVA analysis had a confidence interval of 95 $\%$ (p < 0.05 , i.e., a $5 \%$ significance level). All statistical analyses were made using the Graphpad PRISM 5.0 program (Graphpad Software, Inc., San Diego, California).

\subsection{The potential economic and environmental impact of bioaugmentation}

In order to define the effect of bioaugmentation on the energy production and the GHG emissions of the biogas reactor compared to a reactor operating under ammonia induced inhibited-steady-state the following assumptions were made:

1. The $\mathrm{CO}_{2}$ equivalent was calculated as $25 \mathrm{t} \mathrm{CO}_{2}$ equivalent per $\mathrm{CH}_{4}$ (IPCC, 2013).

2. Both reactors had zero GHG emissions.

3. The upper calorific value of methane was used $\left(11.04 \mathrm{kWh} \mathrm{m}^{-3} \mathrm{CH}_{4}\right)$ to evaluate the energy recovery from the bioaugmentation (Schley et al., 2010).

4. The electricity production efficiency from biogas in a typical CHP unit was determined to be $40 \%$ (Uusitalo et al., 2016)

5. The tariff of electrical power produced from a CHP unit combusting biogas in EU is between 0.11 and $0.28 € \mathrm{kWh}^{-1}$ (European Biogas Association, 2015).

To approximate the increase from the bioaugmentation of the annual gross revenue of a typical full-scale, manure-based biogas reactor operating under inhibited-steady-state, it was assumed that:

1. The reactor's operational size was $5,000 \mathrm{~m}^{3}$.

2. The feedstock had the same VS content as the feedstock presented in Table 1.

3. The HRT of the reactor was 24 days.

4. The reactor was operating for 330 days per year. 
5. Bioaugmentation improved the biogas production by $36 \%$.

\section{Results and Discussion}

\subsection{Reactors performance}

During P-1, both reactors $\left(\mathrm{R}_{\mathrm{Enc}}\right.$ and $\left.\mathrm{R}_{\mathrm{Ctl}}\right)$ had a statistically similar $(p>0.05)$ average methane production yield (Fig. 1) of $263 \mathrm{~mL} \mathrm{CH}_{4} \mathrm{~g}^{-1} \mathrm{VS}$, at steady-state. defined as a period of ten successive days with less than $10 \%$ variation in the methane production, VFA accumulation and $\mathrm{pH}$ fluctuation (Fotidis et al., 2016). When ammonia levels increased in the feedstock to $3 \mathrm{~g} \mathrm{NH}_{4}{ }^{+}-\mathrm{N} \mathrm{L}^{-1}$ (P-2) and $4 \mathrm{~g} \mathrm{NH}_{4}{ }^{+}-\mathrm{N} \mathrm{L}^{-1}$ (P-3) methane production, at inhibitedsteady-state, was decreased in both reactors between 30 and $43 \%$ compared to P-1. At the beginning of P-4 both reactors briefly recovered some of their lost methane productivity, due to the acclimation of the methanogenic communities to the increased ammonia levels (Chen et al., 2008). Nevertheless, the methane production was inhibited again, and at the end of P-4 was approximately $31 \%$ less for both reactors (at steady-state) compared to P-1. Immediately after bioaugmentation (P-6), the $\mathrm{R}_{\text {Enc }}$ reactor demonstrated a significant improvement in methane production rate, which led to a new uninhibited-steady-state (days 131-142). In this new steady-state, the $\mathrm{R}_{\text {Enc }}$ reactor was operating continuously for approximately two HRTs with approximately $40 \%$ higher methane production rate compared to the inhibited-steadystate at the end of P-4. Surprisingly, the $\mathrm{R}_{\mathrm{Enc}}$ reactor regained $97.2 \%$ of the methane production rate it had before the introduction of the additional ammonia to the feedstock $(\mathrm{P}-$ 1), practically completely overcoming the ammonia inhibitory effect. Contrary to $R_{\text {Enc }}$, the control reactor $\left(\mathrm{R}_{\mathrm{Ctl}}\right)$ remained in an ammonia-induced inhibited-steady-state in P-6, slightly increasing (5\%) its methane production compared to P-4. This statistically significant $(p<0.05)$, but small improvement in methane production, was due to the slow acclimation of the methanogenic populations to the high ammonia levels (Gao et al., 2015). 
Finally, a direct comparison between $\mathrm{R}_{\mathrm{Enc}}$ and $\mathrm{R}_{\mathrm{Ctl}}$ during the final steady-state (days 131142), shows that $\mathrm{R}_{\mathrm{Enc}}$ had an average of more than $36 \%$ higher methane production rate. Overall, the study showed, for the first time, that an enriched ammonia-tolerant methanogenic culture could be successfully used as bioaugmentation inoculum to completely counteract ammonia inhibition in a CSTR reactor. This remediation approach is alternative to conventional methods (dilution and temperature lowering), used today to alleviate ammonia toxicity in AD reactors (Nielsen and Angelidaki, 2008).

\subsection{VFA accumulation and $\mathrm{pH}$ fluctuation}

The total VFA accumulation pattern (Fig. 2) was in consistence with the biomethanation performance of the two reactors. Specifically, both reactors started with low VFA levels during P-1 and P-2. When ammonia negatively affected the reactors at the end of P-2 and during P-3, led to a maximum VFA accumulation (>2,000 $\left.\mathrm{mg} \mathrm{HAc} \mathrm{L}^{-1}\right)$. At that point, both reactors had a transient methane production recovery, probably due to microbial acclimation, which initiated the reduction of the VFA levels at the end of P-3. During P-4, VFA levels were stabilized above $1,000 \mathrm{mg} \mathrm{HAc} \mathrm{L}^{-1}$ for both reactors. After bioaugmentation $(\mathrm{P}-6), \mathrm{R}_{\mathrm{Enc}}$ reactor's VFA dropped below 1,000 $\mathrm{mg} \mathrm{HAc}^{-1}$ and were kept stable within the normal limits for continuous AD of dairy slurry until the end of the experiment (Fang et al., 2011). Contrary to the $\mathrm{R}_{\mathrm{Enc}}$, VFA accumulation (Fig. 2) in $\mathrm{R}_{\mathrm{Ctl}}$ verified that the reactor was at inhibited-steady-state (days 121-142) at $5 \mathrm{~g} \mathrm{NH}_{4}{ }^{+}-\mathrm{N} \mathrm{L}^{-1}$, with VFA levels above the established threshold of $1,500 \mathrm{mg} \mathrm{HAc} \mathrm{L}^{-1}$ while having a stable daily methane production. Despite the VFA accumulation, $\mathrm{pH}$ in both reactors was only slightly reduced throughout the experiment (from 8.15 to 7.7 ), due to the strong buffering capacity attributed to high ammonia content (Liu et al., 2008). 


\subsection{Microbial population richness, diversity and dynamicity}

In this study, next generation sequencing of 16S rRNA gene hypervariable V3 region was chosen to evaluate microorganisms' richness, to assign microbial taxa and to calculate relative abundances. Microbial richness (number of operational taxonomic units-OTUs, at $97 \%$ similarity level) of $\mathrm{R}_{\mathrm{Enc}}$ and $\mathrm{R}_{\mathrm{Ctl}}$ were analysed across two different time points: before (P-4) and after (P-6) bioaugmentation/abiotic augmentation. Quality results of sequencing and complete taxonomic assignment of microbial OTUs are reported in Fig. S2, Table S1 and Data set 1 (Supplementary Material-Part A and Part B).

Alpha and beta diversity indices demonstrated the high dynamicity and diversity in microbial communities most probably due to ammonia toxicity (Fig. 3 and Fig. S3, Supplementary Material-Part A), highlighting opposite trends in archaeal and bacterial communities. Specifically, archaea diversity, after the bioaugmentation (P-6), greatly decreased resulting in a more specialized community. The archaeal community, which was responsible for the biomethanation process, was drastically narrowed its diversity to species more robust to ammonia toxicity. Specifically, a huge reduction in $\mathrm{R}_{\mathrm{Enc}}$ diversity occurred in P-6 (Fig. 3a), indicating that the bioaugmentation inoculum addition most probably escalated the reduction in archaea diversity.

Contrary to archaea, bacteria samples taken before the bioaugmentation/abiotic augmentation clustered closely, while samples taken in P-6 diverged greatly with a high increase in the diversity, especially in $\mathrm{R}_{\text {Enc }}$ (Fig. 3b). These findings strongly suggest that microbial acclimation to ammonia, enhanced the number of bacterial species present in the reactors, with an additional increase in $\mathrm{R}_{\text {Enc }}$ microbial diversity due to bioaugmentation. $\mathrm{A}$ possible explanation is that the bioaugmented hydrogenotrophic methanogens decreased the hydrogen partial pressure, thermodynamically allowing the SAO pathway to evolve (Hattori, 2008) and more SAOB species to thrive. Moreover, the increase in bacterial diversity supports 
the assumption that bacteria are tolerant to ammonia toxicity, which mainly is affecting the methanogenic archaea.

\subsection{Taxonomy composition and microbial variability following the bioaugmentation effect}

A general overview of the microbial community structure showed that Euryarchaeota (96 $\%$ relative abundance) and Crenarchaeota (1\% relative abundance) were the most abundant archaeal phyla. Firmicutes (57\% relative abundance), Bacteroidetes (27\% relative abundance) and WWE1 (4 \% relative abundance) were by far the dominant phyla of bacteria domain.

The archaeal community was dominated by Methanosarcina genus with $94 \%$ relative abundance on average in the different samples. A decreased presence of Methanosarcina (from $95 \%$ to $88 \%$ of relative abundance) was evident when comparing P-4 and P-6 in $\mathrm{R}_{\text {Enc }}$, while its abundance was quite stable in $\mathrm{R}_{\mathrm{Ctl}}$ (slightly increase from $96 \%$ to $98 \%$ in P-6). This is a proof that bioaugmentation has rapidly changed the microbial composition in the bioaugmentation reactor; something that the natural acclimation process cannot achieve (if at all) in such short timeframe.

Methanoculleus genus decreased in both reactors after bioaugmentation/abiotic augmentation. Specifically, a drastic decrease in Methanoculleus genus abundance was observed (from $\sim 1 \%$ to $\sim 0.1 \%$ ) in $\mathrm{R}_{\mathrm{Ctl}}$, while the decrease was weaker in $\mathrm{R}_{\text {Enc }}$ (from $\sim 1 \%$ to $\sim 0.6 \%$ ). Analysis showed no difference in Methanoculleus genus abundance between $\mathrm{R}_{\mathrm{Ctl}}$

and $\mathrm{R}_{\mathrm{Enc}}$ before inocula addition, however, the same comparison after bioaugmentation showed a fourfold increase in abundance of Methanoculleus spp. in $\mathrm{R}_{\text {Enc. Results obtained at }}$ OTUs level indicated the presence of different species of Methanoculleus genus with opposite behaviours. It was demonstrated the occurrence of a Methanoculleus spp. resident and 
abundant in $\mathrm{R}_{\mathrm{Ctl}}$ and $\mathrm{R}_{\mathrm{Enc}}$, before the inocula addition that strongly reduced their abundance after bioaugmentation/abiotic augmentation (from $0.7 \%$ to $0.06 \%$, on average). On the contrary, M. bourgensis increased threefold (from $0.07 \%$ to $0.2 \%$ ) its relative abundance only in $\mathrm{R}_{\mathrm{Enc}}$, indicating the bioaugmentation positive effect. Moreover, this trend is even more evident comparing $\mathrm{R}_{\mathrm{Ctl}}$ and $\mathrm{R}_{\mathrm{Enc}}$ after bioaugmentation/abiotic augmentation where the relative abundance of $M$. bourgensis increased more than 16-fold in $\mathrm{R}_{\mathrm{Enc}}$ (Fig. 4a). It seems that the microbial changes evolved in the $\mathrm{R}_{\mathrm{Enc}}$, were part of the "microbiological domino effect", which has been identified as the main mechanism of a successful bioaugmentation process in anaerobic systems (Fotidis et al., 2014b; Zhang et al., 2015). Since methanogens are known to be crucial players (define the overall process rates) of the SAO pathway (Wang et al., 2015), it seems that in this study methanogens were the bioaugmentation "process steering microbes". As "process steering microbes" are defined the non-dominant microbiological groups that, under specific environmental conditions, can dictate the activity of a microbiological system. Even though, methanogens are non-hub species (i.e. species that are not directly associated with many other species) (Faust and Raes, 2012), it seems that bioaugmentation could give them the pivotal role in determining the overall microbial consortium.

Another interesting finding was the presence of three OTUs of Candidatus nitrososphaera genus increasing in abundance of 16-fold in $\mathrm{R}_{\text {Enc }}$ after bioaugmentation (from $0.2 \%$ to 2.3 $\%)$. This genus belongs to phylum Crenarchaeota, well known as ammonia-oxidizing archaea (AOA). Moreover, the same trend of increased abundance (27-fold) was found in two OTUs classified only at phylum level as Crenarchaeota (from $0.2 \%$ to $1.0 \%$ and from $0.03 \%$ to $0.5 \%$ ). It was demonstrated by Tourna et al. (2011) that the AOA Nitrososphaera viennensis is able to grow at increased ammonia levels with considerably higher growth rates when was grown in co-culture with bacteria, possibly related to Hyphomicrobium spp. and 
Mesorhizobium spp.. It can be postulated that the presence of the bacteria in $\mathrm{R}_{\mathrm{Enc}}$ (after bioaugmentation), enhances the activity and consequently the abundance of $C$. nitrososphaera.

The bacterial community showed higher diversity when compared with archaeal community, although it was possible to obtain taxonomic assignment at genus level only for 20 to $30 \%$ of relatively abundant microbes. This lack in $16 \mathrm{~S}$ rRNA databases is because microorganisms are not yet isolated. Overall, six genera were found to be the most abundant (>1\% of relative abundance, Fig. 4b): Clostridium spp., Caldicoprobacter spp., Alkaliphilus spp., Candidatus, Cloacamonas, Sedimentibacter spp. and Syntrophomonas spp.. All of these genera have members that are known to mediate different processes of the overall AD process (e.g. VFA fermenters, amino acid fermenters, or acetate oxidising bacteria) (Schnürer et al., 1996). It seems that, in this complex anaerobic environment, bacteria were more ammoniatolerant compared to any methanogenic archaea. This would indicate that, at high ammonia concentrations, in the syntrophic relationship between hydrogenotrophic methanogens and SAOB, the methanogens are the most sensitive partners. The increased abundance of Caldicoprobacter spp. has been related before to high ammonia levels $\left(\geq 5 \mathrm{~g} \mathrm{NH}_{4}{ }^{+}-\mathrm{N} \mathrm{L}^{-1}\right)$ in batch anaerobic reactors (Poirier et al., 2016). It seems that Caldicoprobacter spp., a sugar fermenter (Zamanzadeh et al., 2016), becomes substrate competitive to the other sugar fermenting bacteria, due to its increased tolerance to ammonia toxicity.

Finally, it must be mentioned that the microbiological analysis was performed before (day 96, P-4) and one HRT after (day 121, P-6) bioaugmentation, in order to depict the fast changes in the microbial dynamicity, coupling the increased methane production of the reactors that resulted from bioaugmentation. Therefore, methanogenic communities occurred in both reactors later in the experiment (until day 142) were not analysed. Nevertheless, it would be interesting for the future research to assess the dynamicity of the microbiome of the 
bioaugmented anaerobic systems for more HRTs.

\subsection{The significance of bioaugmentation for the biogas industry}

Based on the lab scale experiments, it was estimated that bioaugmentation will improve up to $36 \%$ the energy production, the GHG reduction efficiency and the gross revenue for every ton VS of substrate treated in an ammonia inhibited biogas reactor (Table 2). This significant overall improvement would take place without any changes in the infrastructure or the operational parameters (HRT, temperature, OLR, ammonia-rich substrate etc.) of the biogas reactor. However, it was not in the scope of the current study to assess meticulously the environmental and economic effects of bioaugmentation. To evaluate all the technical, industrial and economic parameters involved, full-scale experimental assessment must be performed. With this in mind, today manure-based biogas plants are in need of finding more types of biomass to use as co-substrates to increase their methane production potential. However, as it was aforementioned, the biogas industry has no established process to efficiently digest the ammonia-rich substrates that are available in vast amounts. If bioaugmentation is used in the industrial level, will allow new ammonia-rich substrates to be introduced in the reactors, without the corresponding drawbacks from the ammonia toxicity effect. This means, that a typical European full-scale, manure based biogas reactor (with $5,000 \mathrm{~m}^{3}$ working volume), could have an increase in the annual gross revenue between 100,000 to $240,000 €$ due to bioaugmentation.

\subsection{Bioaugmentation efficiency of enriched versus pure culture}

A previous study, performed under the same experimental conditions using a pure methanogenic strain (M. bourgensis $\mathrm{MS}^{\mathrm{T}}$ ) as bioaugmentation inoculum, demonstrated a $\sim 90.3 \%$ recovery of the initial uninhibited of methane production (Fotidis et al., 2014b). The comparison between the two studies indicates that the enriched culture alleviated ammonia 
toxicity more efficiently (by $\sim 25 \%$ ) than the pure culture. Additionally, De Roy et al. (2014) stated that the performance of pure cultures could change when they are co-cultivated with complex microbial communities. This behaviour could have significant implications during the bioaugmentation (e.g. unfavourable physicochemical conditions, washout of the bioaugmented culture etc.), which could lead to process failure (Westerholm et al., 2012). These findings strengthen the hypothesis that ammonia-tolerant enriched cultures could potentially be the proper bioaugmentation inocula to alleviate ammonia toxicity in full-scale biogas reactors.

Finally, except of pure strains and enriched cultures, synthetic microbial communities (i.e. co-cultures of two or more specific microbial populations in a controlled environment) (Pandhal and Noirel, 2014) are currently attracting the interest of scientists for engineered inocula that solve specific biotechnological challenges (Großkopf and Soyer, 2014). Up to our knowledge, ammonia-tolerant, synthetic microbial communities have never been tested as bioaugmentation inocula in continuous anaerobic reactors, which could be considered as a viable solution in future applications.

\section{Conclusions}

Cultivation of pure strains of methanogens that can be used as bioaugmentation inocula in ammonia-inhibited anaerobic reactors is connected to technical difficulties compared to enriched cultures. This manuscript presents for the first-time the application of enriched cultures for remediation in ammonia inhibited continuous reactors. This novel approach demonstrated a $100 \%$ recovery of the inhibited $\mathrm{AD}$ process after bioaugmentation with an ammonia-tolerant methanogenic enriched culture with potential economic and environmental benefits. Since enriched culture improved methane production more than $40 \%$, it was $25 \%$ 
more effective biomethanation inoculum compared to a pure strain (M. bourgensis MS2T).

Finally, the addition of the enriched culture, triggered a shift of the microbial composition, resulting to lower archaeal community diversity, composed by species more tolerant to ammonia.

\section{Acknowledgments}

The current work was supported by Energinet.dk under the project framework ForskEL "MicrobStopNH $\mathrm{N}_{3}$-Innovative bioaugmentation strategies to tackle ammonia inhibition in AD process" (program no. 2015-12327).

\section{References}

APHA, 2012. Standard Methods for the Examination of Water and Wastewater, in: Rice, E.W., Baird, R.B., Eaton, A.D., Clesceri, L.S. (Eds.), American Public Health Association, American Water Works Association, Water Environment Federation, Washington DC, USA.

Chen, Y., Cheng, J.J., Creamer, K.S., 2008. Inhibition of anaerobic digestion process: a review. Bioresour. Technol. 99, 4044-4064.

Costa, J.C., Barbosa, S.G., Alves, M.M., Sousa, D.Z., 2012. Thermochemical pre- and biological co-treatments to improve hydrolysis and methane production from poultry litter. Bioresour. Technol. 111, 141-147.

De Roy, K., Marzorati, M., Van den Abbeele, P., Van de Wiele, T., Boon, N., 2014. Synthetic microbial ecosystems: an exciting tool to understand and apply microbial communities. Environ. Microbiol. 16, 1472-1481.

Dokianakis, S.N., Kornaros, M.E., Lyberatos, G., 2004. On the effect of pharmaceuticals on bacterial nitrite oxidation. Water Sci. Technol. 50, 341-346.

Duan, N., Dong, B., Wu, B., Dai, X., 2012. High-solid anaerobic digestion of sewage sludge 
under mesophilic conditions: Feasibility study. Bioresour. Technol. 104, 150-156.

European Biogas Association, 2015. Annual statistical report of the European Biogas Association on the European anaerobic digestion industry and markets. Brussels, Belgium, (Last accessed: August 17, 2017) http://europeanbiogas.eu/2015/12/16/biogasreport2015/.

Fang, C., Boe, K., Angelidaki, I., 2011. Anaerobic co-digestion of by-products from sugar production with cow manure. Water Res. 45, 3473-3480.

Faust, K., Raes, J., 2012. Microbial interactions: from networks to models. Nat. Rev. Microbiol. 10, 538-550.

Fotidis, I.A., Karakashev, D., Angelidaki, I., 2014a. The dominant acetate degradation pathway/methanogenic composition in full-scale anaerobic digesters operating under different ammonia levels. Int. J. Environ. Sci. Technol. 11, 2087-2094.

Fotidis, I.A., Karakashev, D., Kotsopoulos, T.A., Martzopoulos, G.G., Angelidaki, I., 2013. Effect of ammonium and acetate on methanogenic pathway and methanogenic community composition. FEMS Microbiol. Ecol. 83, 38-48.

Fotidis, I.A., Laranjeiro, T.F.V.C., Angelidaki, I., 2016. Alternative co-digestion scenarios for efficient fixed-dome reactor biomethanation processes. J. Cleaner Prod. 127, 610-617.

Fotidis, I.A., Wang, H., Fiedel, N.R., Luo, G., Karakashev, D.B., Angelidaki, I., 2014b. Bioaugmentation as a solution to increase methane production from an ammonia-rich substrate. Environ. Sci. Technol. 48, 7669-7676.

Gao, S., Zhao, M., Chen, Y., Yu, M., Ruan, W., 2015. Tolerance response to in situ ammonia stress in a pilot-scale anaerobic digestion reactor for alleviating ammonia inhibition. Bioresour. Technol. 198, 372-379.

Großkopf, T., Soyer, O.S., 2014. Synthetic microbial communities. Curr. Opin. Microbiol. 18, 72-77. 
Han, W., Liu, Z., Fang, J., Huang, J., Zhao, H., Li, Y., 2016. Techno-economic analysis of dark fermentative hydrogen production from molasses in a continuous mixed immobilized sludge reactor. J. Cleaner Prod. 127, 567-572.

Hattori, S., 2008. Syntrophic acetate-oxidizing microbes in methanogenic environments. Microbes Environ. 23, 118-127.

Herbes, C., Braun, L., Rube, D., 2016. Pricing of Biomethane Products Targeted at Private Households in Germany—Product Attributes and Providers' Pricing Strategies. Energies 9, 252.

IPCC, 2013. Climate Change 2013: The Physical Science Basis. Working Group I Contribution to the Fifth Assessment Report of the Intergovernmental Panel on Climate Change, in: Stocker, T., Qin, D., Plattner, G., Tignor, M., Allen, S., Boschung, J., Nauels, A., Xia, Y., Bex, B., Midgley, B. (Eds.), Cambridge University Press, Cambridge, United Kingdom and New York, NY, USA.

Kelleher, B.P., Leahy, J.J., Henihan, A.M., O'Dwyer, T.F., Sutton, D., Leahy, M.J., 2002. Advances in poultry litter disposal technology - a review. Bioresour. Technol. 83, $27-$ 36.

Kovács, E., Wirth, R., Maróti, G., Bagi, Z., Rákhely, G., Kovács, K.L., 2013. Biogas production from protein-rich biomass: Fed-batch anaerobic fermentation of casein and of pig blood and associated changes in microbial community composition. PLOS ONE $8, \mathrm{e} 77265$.

Liu, C.F., Yuan, X.Z., Zeng, G.M., Li, W.W., Li, J., 2008. Prediction of methane yield at optimum $\mathrm{pH}$ for anaerobic digestion of organic fraction of municipal solid waste. Bioresour. Technol. 99, 882-888.

Luo, G., Wang, W., Angelidaki, I., 2013. Anaerobic digestion for simultaneous sewage sludge treatment and $\mathrm{CO}$ biomethanation: process performance and microbial ecology. 
Environ. Sci. Technol. 47, 10685-10693.

Massé, D.I., Rajagopal, R., Singh, G., 2014. Technical and operational feasibility of psychrophilic anaerobic digestion biotechnology for processing ammonia-rich waste. Appl. Energy 120, 49-55.

Moestedt, J., Muller, B., Westerholm, M., Schnürer, A., 2016. Ammonia threshold for inhibition of anaerobic digestion of thin stillage and the importance of organic loading rate. Microb. Biotechnol. 9, 180-194.

Narihiro, T., Nobu, M.K., Kim, N.-K., Kamagata, Y., Liu, W.-T., 2015. The nexus of syntrophy-associated microbiota in anaerobic digestion revealed by long-term enrichment and community survey. Environ. Microbiol. 17, 1707-1720.

Nielsen, H.B., Angelidaki, I., 2008. Codigestion of manure and industrial organic waste at centralized biogas plants: process imbalances and limitations. Water Sci. Technol. 58, $1521-1528$.

Pandhal, J., Noirel, J., 2014. Synthetic microbial ecosystems for biotechnology. Biotechnol. Lett. 36, 1141-1151.

Poirier, S., Desmond-Le Quéméner, E., Madigou, C., Bouchez, T., Chapleur, O., 2016. Anaerobic digestion of biowaste under extreme ammonia concentration: Identification of key microbial phylotypes. Bioresour. Technol. 207, 92-101.

Rajagopal, R., Masse, D.I., Singh, G., 2013. A critical review on inhibition of anaerobic digestion process by excess ammonia. Bioresour. Technol. 143, 632-641.

Schley, P., Beck, M., Uhrig, M., Sarge, S., Rauch, J., Haloua, F., Filtz, J.-R., Hay, B., Yakoubi, M., Escande, J., 2010. Measurements of the calorific value of methane with the new GERG reference calorimeter. International Journal of Thermophysics 31, 665679.

Schnürer, A., Schink, B., Svensson, B.H., 1996. Clostridium ultunense sp. nov., a mesophilic 
bacterium oxidizing acetate in syntrophic association with a hydrogenotrophic methanogenic bacterium. Int. J. Syst. Bacteriol. 46, 1145-1152.

Sivagurunathan, P., Sen, B., Lin, C.-Y., 2015. High-rate fermentative hydrogen production from beverage wastewater. Appl. Energy 147, 1-9.

Tampio, E., Marttinen, S., Rintala, J., 2016. Liquid fertilizer products from anaerobic digestion of food waste: mass, nutrient and energy balance of four digestate liquid treatment systems. J. Cleaner Prod. 125, 22-32.

Tian, H., Fotidis, I.A., Mancini, E., Angelidaki, I., 2017. Different cultivation methods to acclimatise ammonia-tolerant methanogenic consortia. Bioresour. Technol. 232, 1-9.

Tourna, M., Stieglmeier, M., Spang, A., Könneke, M., Schintlmeister, A., Urich, T., Engel, M., Schloter, M., Wagner, M., Richter, A., 2011. Nitrososphaera viennensis, an ammonia oxidizing archaeon from soil. Proc. Natl. Acad. Sci. U.S.A. 108, 8420-8425.

Uusitalo, A., Uusitalo, V., Grönman, A., Luoranen, M., Jaatinen-Värri, A., 2016. Greenhouse gas reduction potential by producing electricity from biogas engine waste heat using organic Rankine cycle. J. Cleaner Prod. 127, 399-405.

Venkiteshwaran, K., Milferstedt, K., Hamelin, J., Zitomer, D.H., 2016. Anaerobic digester bioaugmentation influences quasi steady state performance and microbial community. Water Res. 104, 128-136.

Wang, H., Fotidis, I.A., Angelidaki, I., 2015. Ammonia effect on hydrogenotrophic methanogens and syntrophic acetate-oxidizing bacteria. FEMS Microbiol. Ecol. 91, fiv130.

Westerholm, M., Dolfing, J., Sherry, A., Gray, N.D., Head, I.M., Schnürer, A., 2011. Quantification of syntrophic acetate-oxidizing microbial communities in biogas processes. Environ. Microbiol. Rep. 3, 500-505.

Westerholm, M., Levén, L., Schnürer, A., 2012. Bioaugmentation of syntrophic acetate- 
oxidizing culture in biogas reactors exposed to increasing levels of ammonia. Appl. Environ. Microbiol. 78, 7619-7625.

Westerholm, M., Moestedt, J., Schnürer, A., 2016. Biogas production through syntrophic acetate oxidation and deliberate operating strategies for improved digester performance. Appl. Energy 179, 124-135.

Westerholm, M., Muller, B., Isaksson, S., Schnürer, A., 2015. Trace element and temperature effects on microbial communities and links to biogas digester performance at high ammonia levels. Biotechnol. Biofuels 8, 154.

Wilson, L.P., Loetscher, L.H., Sharvelle, S.E., De Long, S.K., 2013. Microbial community acclimation enhances waste hydrolysis rates under elevated ammonia and salinity conditions. Bioresour. Technol. 146, 15-22.

Yenigün, O., Demirel, B., 2013. Ammonia inhibition in anaerobic digestion: A review. Process Biochem. 48, 901-911.

Zamanzadeh, M., Hagen, L.H., Svensson, K., Linjordet, R., Horn, S.J., 2016. Anaerobic digestion of food waste - Effect of recirculation and temperature on performance and microbiology. Water Res. 96, 246-254.

Zehnder, A.J., Huser, B.A., Brock, T.D., Wuhrmann, K., 1980. Characterization of an acetatedecarboxylating, non-hydrogen-oxidizing methane bacterium. Arch. Microbiol. 124, 111.

Zhang, J., Guo, R.-B., Qiu, Y.-L., Qiao, J.-T., Yuan, X.-Z., Shi, X.-S., Wang, C.-S., 2015. Bioaugmentation with an acetate-type fermentation bacterium Acetobacteroides hydrogenigenes improves methane production from corn straw. Bioresour. Technol. 179, 306-313. 


\section{Figure Captions}

Fig. 1. Methane production yield of the CSTR reactors. Error bars denote standard deviation from the mean of triplicate measurements of the biogas methane content $(n=3)$.

Fig. 2. Total VFA accumulation (expressed in acetate equivalent) and $\mathrm{pH}$ fluctuation in the CSTR reactors. Error bars denote standard deviation from the mean of triplicate measurements of the VFA (n $=3)$.

Fig. 3. Principal coordinate analysis describes archaeal a) and bacterial b) communities richness and variability indicated before (Pre) and after (Post) bioaugmentation/abiotic augmentation in $R_{\text {Enc }}$ and $\mathrm{R}_{\mathrm{Clt}}$. Only the first two principal components are shown.

Fig. 4. Relative abundance identified for the most interesting a) archaea and b) bacteria are represented as a heat map (left part), to evidence folds' change (right part) and indicated before (Pre) and after (Post) bioaugmentation/abiotic augmentation in $\mathrm{R}_{\mathrm{Enc}}$ and $\mathrm{R}_{\mathrm{Clt}}$. 
Table 1. Characteristics of the inoculum and the feedstock used in the CSTR reactors $(n=3$, $\mathrm{SD})$

\begin{tabular}{|c|c|c|}
\hline \multirow[t]{2}{*}{ Parameter } & Inoculum & Feedstock \\
\hline & Value \pm SD & Value \pm SD \\
\hline $\mathrm{TS}^{\mathrm{a}}\left(\mathrm{g} \cdot \mathrm{L}^{-1}\right)$ & $29.9 \pm 0.2$ & $56.1 \pm 0.1$ \\
\hline $\mathrm{VS}^{\mathrm{b}}\left(\mathrm{g} \cdot \mathrm{L}^{-1}\right)$ & $18.5 \pm 0.1$ & $41.7 \pm 0.2$ \\
\hline Total Kjeldahl nitrogen $\left(\mathrm{g} \mathrm{N} \mathrm{L}^{-1}\right)$ & $4.0 \pm 0.2$ & $2.7 \pm 0.1$ \\
\hline Total ammonia $\left(\mathrm{g} \mathrm{NH}_{4}{ }^{+}-\mathrm{N} \cdot \mathrm{L}^{-1}\right)$ & $3.2 \pm 0.2$ & $1.7 \pm 0.1$ \\
\hline $\mathrm{pH}$ & & 7.2 \\
\hline Total VFA ${ }^{\mathrm{c}}\left(\mathrm{g} \mathrm{L}^{-1}\right)$ & $2.2 \pm 0.3$ & $11.0 \pm 0.9$ \\
\hline
\end{tabular}

${ }^{\mathrm{a}}$ Total solids, ${ }^{\mathrm{b}}$ Volatile solids, ${ }^{\mathrm{c}}$ Volatile fatty acids 
Table 2. Preliminary approximation of the impact of bioaugmentation on the energy production, the GHG reduction efficiency and the gross profit of manure based biogas reactors ${ }^{\mathrm{a}}(\mathrm{n}=3, \mathrm{SD})$

Bioaugmentation Without Difference

bioaugmentation

Electrical energy

$\left(\mathrm{kWh}_{(\mathrm{e})} \mathrm{t}^{-1} \mathrm{VS}\right)$

$\mathrm{CO}_{2}$ Equivalent

$\left(\mathrm{t} \mathrm{CO} 2\right.$ Eq. $\left.\mathrm{t}^{-1} \mathrm{VS}\right)$

Minimum gross revenue

$\left(€ \mathrm{t}^{-1} \mathrm{VS}\right)$

Maximum gross revenue

$314.4 \pm 5.0$

$231.0 \pm 6.6$

$3.3 \pm 0.1$

$4.5 \pm 0.1$

$134.7 \pm 2.1$

$99.0 \pm 2.8$
$298 \pm 17.1$

$824.9 \pm 23.6$

$1.2 \pm 0.1$

$35.7 \pm 2.0$

$\left(€ \mathrm{t}^{-1} \mathrm{VS}\right)$

\footnotetext{
${ }^{a}$ Overall it was assumed that: 1) the reactor size was $5,000 \mathrm{~m}^{3}, 2$ ) the HRT was 24 days, 3) the reactor was operating for 330 days per year, 4) the bioaugmentation improved the production by $36 \%, 5$ ) the $\mathrm{CO}_{2}$ equivalent was $25 \mathrm{t} \mathrm{CO}_{2}$ equivalent $\mathrm{t}^{-1} \mathrm{CH}_{4}$, 6) the upper calorific value of methane was $11.04 \mathrm{kWh}$ $\left.\mathrm{m}^{-3} \mathrm{CH}_{4}, 7\right)$ the electricity production efficiency was $40 \%, 8$ ) the tariff of electrical power was $0.11-0.28$ $€ \mathrm{kWh}^{-1}$ and 9) both reactors had zero GHG emissions.
} 


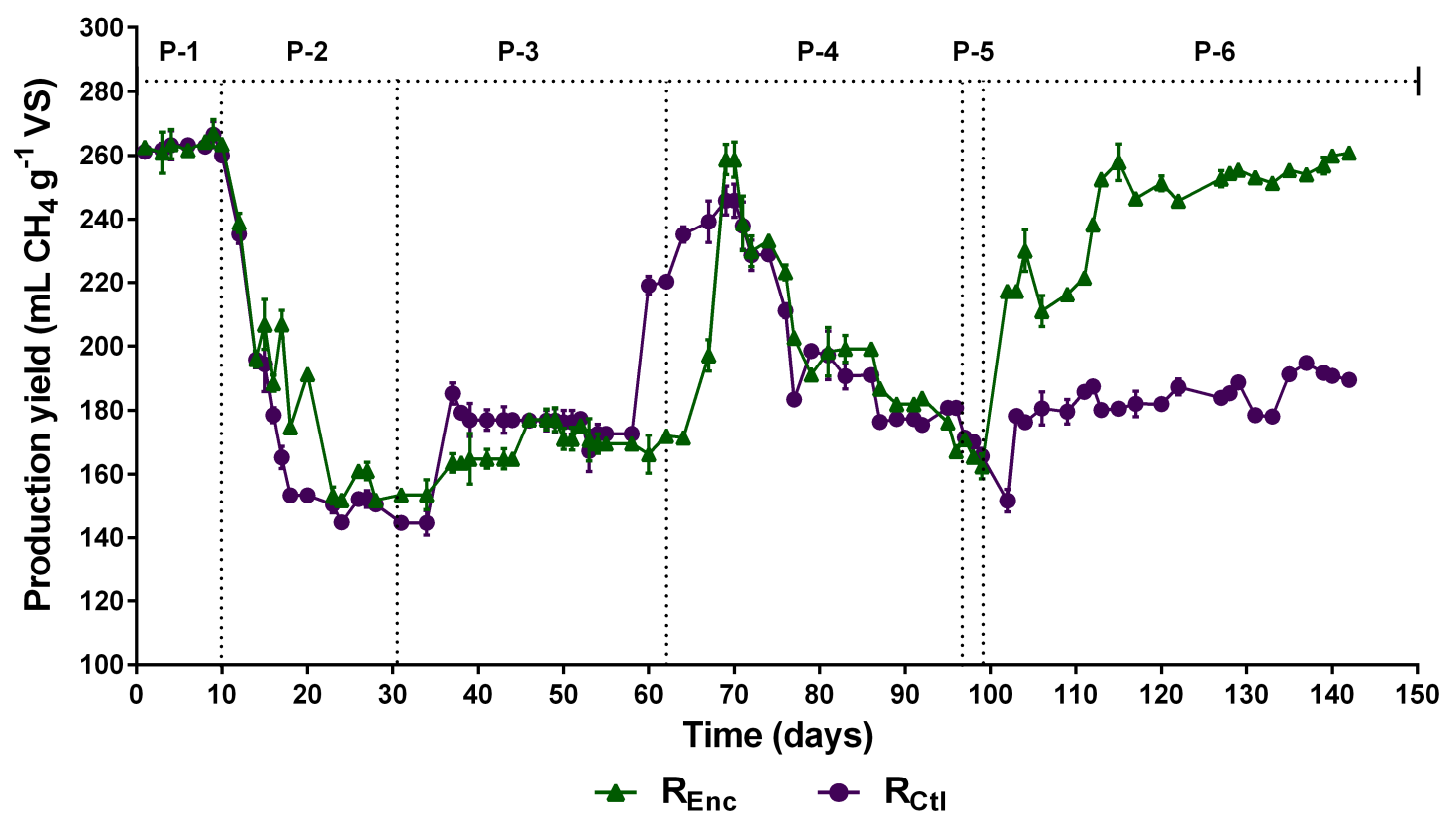




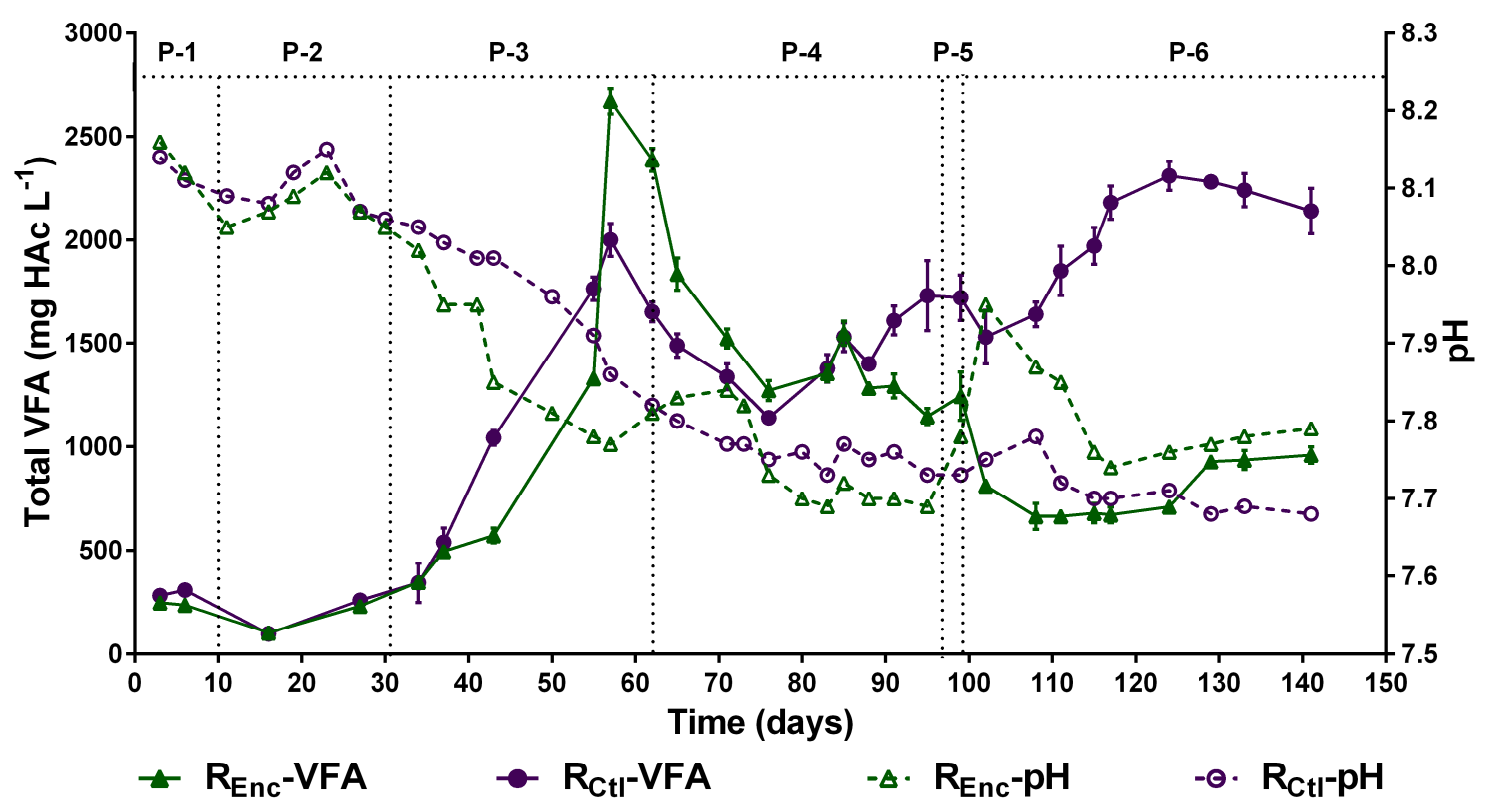




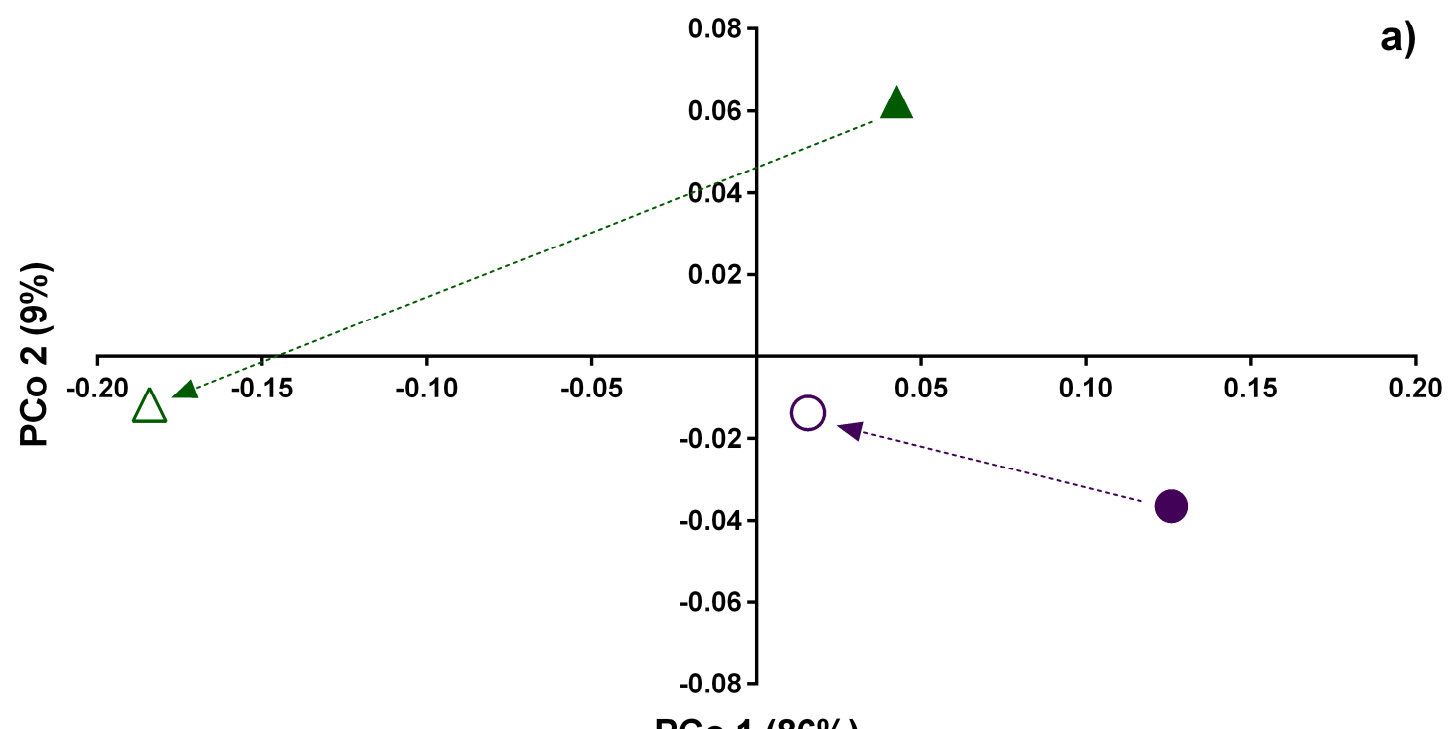

PCo $1(86 \%)$

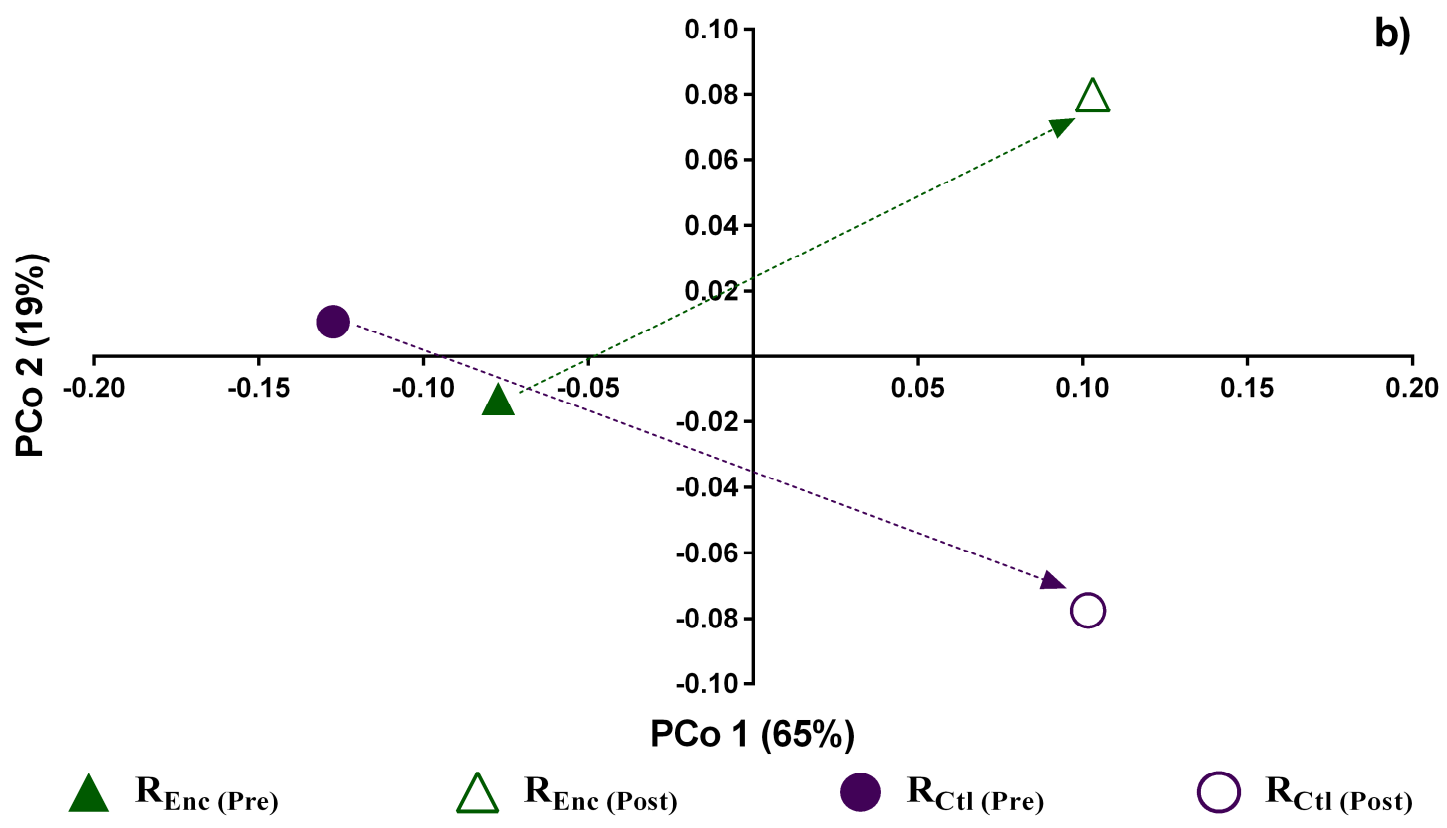



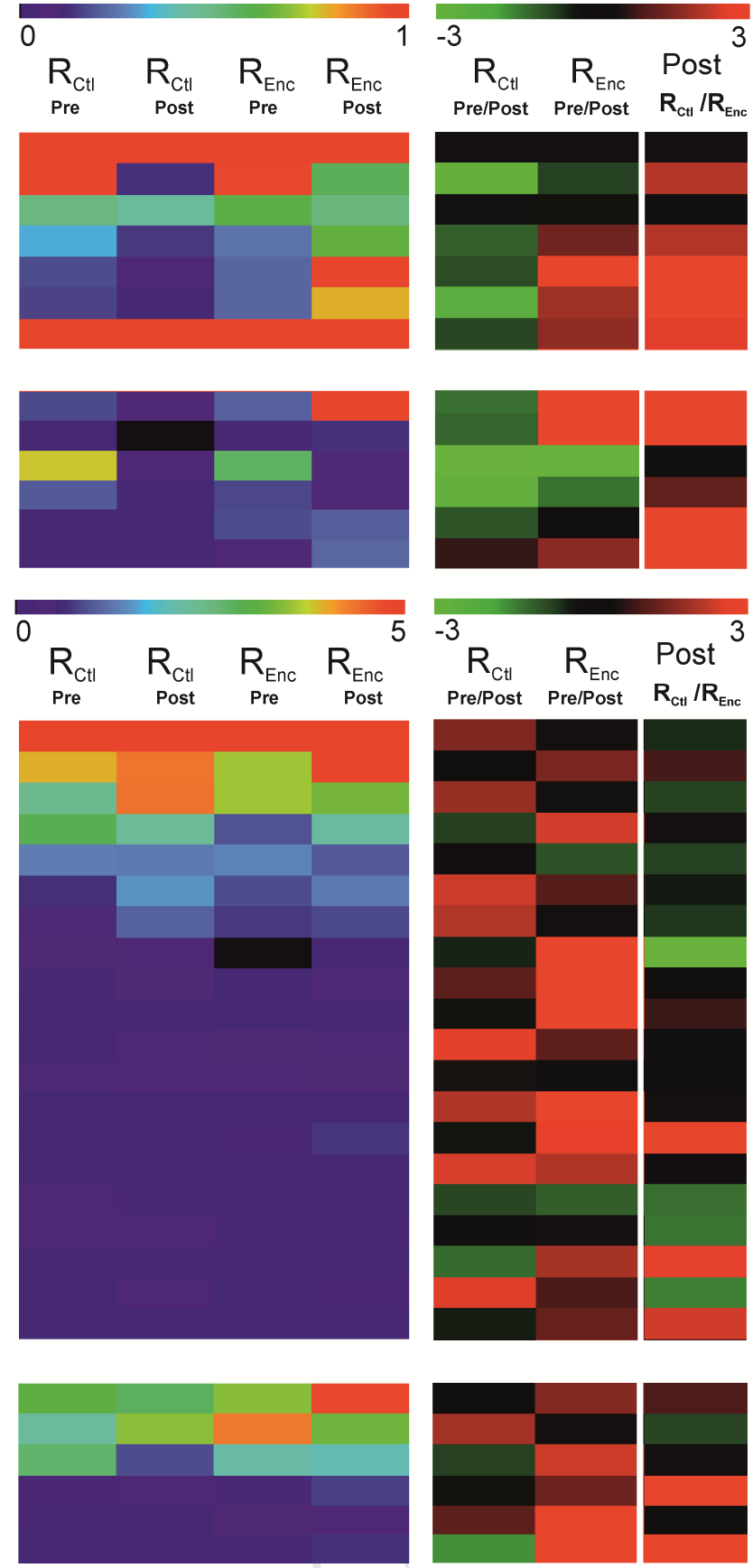

\section{Archaea}

a)

Genus

Methanosarcina

Methanoculleus

Methanobrevibacter

Methanosaeta

Candidatus Nitrososphaera

Methanomassiliicoccaceae clade VadinCA11

higher taxonomical levels

\section{OTUs}

Candidatus Nitrososphaera SCA1145 (00229:00398)

Candidatus Nitrososphaera SCA1145 (756973)

Methanoculleus sp. (00051:00486)

Methanoculleus sp. (00046:00764)

Methanoculleus bourgensis (00286:01728)

Methanoculleus bourgensis (00431:00540)

\section{Bacteria}

b)

\section{Genus}

Clostridium

Caldicoprobacter

Alkaliphilus

Candidatus Cloacamonas

Sedimentibacter

Syntrophomonas

Turicibacter

Paludibacter

Ruminofilibacter

Treponema

Proteiniphilum

Proteiniclasticum

Gallicola

RFN20 (Erysipelotrichaceae)

Brachybacterium

Petrimonas

Acholeplasma

Tannerella

Butyrivibrio

Aminobacterium

\section{OTUs}

Caldicoprobacter (4472825)

Alkaliphilus (759378)

Candidatus Cloacamonas (00036:00693)

Syntrophomonas (00035:00598)

Ruminofilibacter (00011:02101)

Erysipelotrichaceae RFN20 (00034:01987) 


\section{Highlights}

- An enriched culture successfully remediated an ammonia inhibited continuous reactor

- $36 \%$ improvement on energy production, on GHG reduction and on revenue was achieved

- An immediate recovery of the ammonia inhibited biomethanation process was achieved

- An enriched culture was a better bioaugmentation inoculum compared to a pure strain

- Bioaugmentation was performed without excluding the ammonia-rich feedstock 